\title{
PENERAPAN PERENCANAAN MATERIAL PRODUK TAHU PUTIH KUNING DENGAN METODE MATERIAL REQUIREMENT PLANNING (MRP) PADA PABRIK AYPSU BOJONG NANGKA KABUPATEN TANGERANG
}

\author{
Hermanto $^{1}$, Widiyarini' ${ }^{2}$, Dona Fitria ${ }^{3}$ \\ ${ }^{1,2}$ Prodi Teknik Industri, FTIK, Universitas Indraprasta PGRI \\ ${ }^{3}$ Program Studi Pendidikan Ekonomi, FIPPS, Universitas Indraprasta PGRI \\ ${ }^{1,2,3}$ Pascasarjana Doktor Ilmu Ekonomi, Universitas Borobudur Jakarta \\ Email: hers3sm@gmail.com \\ Email: widiya2513@gmail.com \\ Email: fitriaqinthar@gmail.com
}

Dikirim: 8 Mei 2020; Direvisi: 10 Agustus, 2020; Dipublikasikan: 24 Desember 2020

\begin{abstract}
ABSTRAK
Setiap perusahaan, dari perusahaan kecil, menengah sampai perusahaan besar, persediaan sangat penting bagi kelangsungan perusahaan untuk tetap berproduksi dan beroperasi. Perusahaan harus bisa memperkirakan jumlah persediaan yang dimiliki. Tujuan penelitian ini adalah untuk mengetahui kebutuhan material produk tahu yang optimal, dan untuk membuat perencanaan dan pengendalian persediaan bahan baku tahu. Metode yang digunakan dalam penelitian ini adalah metode Material Requirement Planning. Selain itu metode yang digunakan dalam peramalan adalah metode moving average menggunakan software winQSB berdasarkan pola data penjualan. Setelah dilakukan analisis dan pembahasan, penulis dapat menyimpulkan bahwa kebutuhan kedelai dalam pembuatan satu papan tahu $1,5 \mathrm{~kg}$, banyaknya minyak goreng yang dibutuhkan untuk satu papan tahu $0,16 \mathrm{~kg}$, banyaknya air cuka yang dibutuhkan untuk satu papan tahu 0,048 botol, dan banyaknya air yang dibutuhkan untuk satu papan tahu 2,9 liter.
\end{abstract}

Kata kunci: Perencanaan Bahan Baku, Persediaan Bahan Baku, Usaha Produksi tahu Material Requirement Planning

\section{ABSTRACT}

Every company, from small, medium and large companies, inventory is very important for the continuity of the company to keep producing and operating. Companies must be able to estimate the amount of inventory they have. The purpose of this study was to determine the material requirements of the optimal tofu products, and to plan and control the inventory of tofu raw materials. The method used in this study is the Material Requirement Planning method. In addition, the method used in forecasting is the moving average method using winQSB software based on sales data patterns. After analysis and discussion, the author can conclude that the need for soybeans in making one board knows $1.5 \mathrm{~kg}$, the amount of cooking oil needed for one board knows $0.16 \mathrm{~kg}$, the amount of vinegar needed for one board knows 0.048 bottles, and the amount of water needed for one board knows 2.9 liters.

Keywords: Raw Material Planning, Raw Material Inventory, Production Business Tofu Material Requirement Planning 
Volume 12, No. 3, Desember 2020, pp. 206-212

e-ISSN: 2502-5449

p-ISSN: 2085-2266

DOI : $10.30998 /$ sosioekons.v12i3.6376

\section{PENDAHULUAN}

Dalam segala bidang industri yang ada persaingan satu sama lain agar pihaknya dapat menjadi yang paling unggul diantara pesaing-pesaingnya. Persaingan industri di Indonesia terjadi baik dari industri skala besar, skala menengah, skala kecil, dan juga industri pemerintahan. Industri yang ada memiliki cara tersendiri dalam meningkatkan kualitas industrinya agar dapat bersaing, diantaranya adalah meningkatkan kualitas dari produknya, meningkatkan kualitas dari sumber dayanya, dan juga melakukan perbaikan dari sistem produksi. Untuk mengadakan kegiatan produksi harus ada bahan baku. Oleh karena itu didalam dunia usaha masalah bahan baku adalah masalah yang sangat penting. Sehingga diperlukan pengendalian persediaan bahan baku yang efektif dan efisien. (Indrajit \& Djokopranoto, 2013)

Permasalahan yang sering terjadi adalah terdapat kondisi dimana tingginya biaya persediaan yang disebabkan oleh persediaan bahan yang berlebih. Dan masalah lainnya adalah terjadinya kondisi dimana kebutuhan untuk produksi tidak terpenuhi yang disebabkan oleh kurangnya persediaan bahan yang ada sehingga tidak mencukupi kebutuhan produksinya sehingga permintaan pelanggan tidak terpenuhi. Oleh sebab itu perlu dilakukan perbaikan dalam strategi perencanaan persediaan bahan baku untuk produksi, dalam rangka mengantisipasi terjadinya ketidak tersediaan produk pada saat permintaan barang terjadi. Maka dilakukan pendekatan dalam hal perbaikan perencanaan persediaan material produksi dalam mengatasi permasalahan tersebut dengan teknik dan metode yang dianggap mumpuni dan cukup baik dalam mengatasi permasalahan dalam sebuah tata kelola home insdutri.

Pada setiap tingkat usaha, baik usaha kecil, menengah maupun usaha dalam bentuk perusahaan besar, persediaan sangat penting bagi kelangsungan hidup usaha. Setiap usaha harus dapat memperkirakan jumlah persediaan yang dimilikinya. Persediaan yang dimiliki oleh perusahaan tidak boleh terlalu banyak dan juga tidak boleh terlalu sedikit karena akan mempengaruhi biaya yang akan dikeluarkan untuk persediaan tersebut. Jika bahan baku yang tersedia di gudang terlalu banyak, maka akan menyebabkan biaya persediaan yang tinggi, sedangkan modal setiap usaha berbeda-beda dan untuk industri skala menengah dan kecil cenderung terbatas. Sebaliknya, apabila persediaan bahan baku terlalu sedikit, maka akan menghambat perusahaan dalam memenuhi permintaan dari pelanggan. Ketidak pastian jumlah dan waktu permintaan pelanggan mendorong adanya persediaan. Menurut (Viale, 2015). Persediaan adalah hal yang sangat penting bagi perusahaan, terutama perusahaan manufaktur, untuk menunjang kelancaran proses produksi dalam memenuhi permintaan pelanggan. Maka dilakukan pendekatan dalam hal perbaikan perencanaan persediaan material produksi dalam mengatasi permasalahan tersebut dengan teknik dan metode yang dianggap mumpuni dan cukup baik dalam mengatasi permasalahan dalam sebuah tata kelola home insdutri.

Maka dilakukan pendekatan dalam hal perbaikan perencanaan persediaan material produksi dalam mengatasi permasalahan tersebut dengan teknik dan metode yang dianggap mumpuni dan cukup baik dalam mengatasi permasalahan dalam sebuah tata kelola home insdutri. Data dapat dilihat pada table dibawah ini.

Tabel 1. Persediaan Bahan Baku Kacang Kedelai

Periode Desember 2018 sampai November 2019

\begin{tabular}{lcc}
\hline \multicolumn{1}{c}{ Bulan } & $\begin{array}{c}\text { Jumlah order } \\
\text { Kacang kedelai }\end{array}$ & $\begin{array}{c}\text { Banyak Simpanan } \\
\text { Kacang Kedelai }\end{array}$ \\
\hline Desember (2018) & 15500 & 1070 \\
Januari (2019) & 15500 & 1070 \\
Februari (2019) & 15500 & 1070 \\
Maret (2019) & 15500 & 1070 \\
April (2019) & 14500 & 1070
\end{tabular}


Volume 12, No. 3, Desember 2020, pp. 206-212

e-ISSN: $2502-5449$

p-ISSN: 2085-2266

DOI : $10.30998 /$ sosioekons.v12i3.6376

\begin{tabular}{lcc} 
Mei (2019) & 15500 & - \\
Juni (2019) & 13500 & - \\
Juli (2019) & 15500 & 1060 \\
Agustus (2019) & 14300 & 1060 \\
September (2019) & 13200 & 1050 \\
Oktober (2019) & 14400 & 800 \\
Nopember (2019) & 14300 & 900 \\
Jumlah & $\mathbf{1 7 7 2 0 0}$ & $\mathbf{1 0 2 2 0}$ \\
\hline
\end{tabular}

Dari permasalahan tersebut, perusahaan memerlukan penerapan dari perencanaan dan pengendalian persediaan bahan yang baik. ((Sofjan, 2014)). Persediaan berfungsi untuk menghubungkan operasi perusahaan dengan pembelian bahan baku untuk selanjutnya diolah menjadi barang atau jasa yang kemudian diarahkan pada konsumen. ((Baroto, 2012)). Adanya persediaan memungkinkan terlaksananya operasi produksi bagi perusahaan. Salah satu pokok kajian penerapan dari perencanaan dan pengendalianyang membahas perencanaan dan pengendalian persediaan bahan adalah sistem Material Requirement Planning (MRP). Material Requirement Planning (MRP) adalah suatu prosedur logis berupa aturan keputusan dan teknik transaksi berbasis komputer yang dirancang untuk mengolah jadwal induk produksi menjadi kebutuhan bersih untuk semua item.(Gazpersz \& Vincent, 2011). Tujuan dari MRP adalah untuk mengendalikan tingkat persediaan, menentukan prioritas operasi pada masing-masing item dan merencanakan kapasitas sistem produksi secara detail tingkat persediaan mencakup pemesanan item dengan jumlah dan waktu yang tepat.

Berdasarkan dari permasalahan permasalahan tersebut, peneliti memutuskan untuk melakukan penelitian di usaha pembuatan produksi tahu dengan judul penerapan perencenaan persediaan material produk tahu dengan metode Material Requirement Planning (MRP) pada pabrik tahu Ayipsu, dengan jadwal penelitian dimulai dari awal bulan februari tahun 2019 sampai dengan akhir bulan april tahun 2019 untuk mengambil data - data persedian bahan baku produksi tahu. Penelitian ini diharapkan dapat membantu dan mendapatkan perencanaan persediaan bahan baku yang benar benar optimal.

\section{METODE}

Metode Penelitian ini dilakukan dengan tiga cara, menurut (Sugiyono, 2015). yang pertama yaitu dengan penelitian kepustakaan dengan cara mengumpulkan data-data yang berkaitan dengan objek penelitian dari sumber berbagai literator seperti buku, jurnal terdahulu dan internet. Yang kedua adalah dengan Observasi non partisipan yang merupakan suatu pengumpulan data yang dilakukan dengan cara peneliti tidak terlibat dan hanya sebagai pengamat independen, dengan mengumpulkan data-data sekunder yang berupa laporan persediaan bahan baku kacang kedelai periode Desember 2018 - November 2019. Yang ketiga yaitu metode dokumentasi dengan pengumpulan data cukup dengan menyalin data yang ada

Penelitian ini dilaksanakan dari bulan Januari 2019 hingga bulan Mei 2019 dengan menggunakan data-data yang diperoleh dari bagian administrasi usaha pabrik Tahu AYIPSU. Penelitian ini menggunakan data sekunder yang bersifat kualitatif maupun kuantitatif. Data sekunder yang digunakan antara lain: laporan persediaan bahan baku kacang kedelai periode Desember 2018 - November 2019 biaya pembelian bahan baku tahu selama periode Desember 2018 sampai November 2019 dan Kebutuhan bahan baku selama satu tahun . 
Volume 12, No. 3, Desember 2020, pp. 206-212

e-ISSN: 2502-5449

p-ISSN: 2085-2266

DOI : 10.30998/sosioekons.v12i3.6376

\section{HASIL DAN PEMBAHASAN}

Dari pengolahan data yang sudah dilakukan, dapat dilihat hasil analisa perencanaan pengendalian persediaan bahan baku tahu. Analisis yang pertama yaitu menentukan hasil peramalan penjualan pada tiap periode. Hasil peramalan penjualan tahu goreng dan tahu potong dapat dilihat pada tabel dibawah ini.

Tabel 2. Rangkuman Hasil Peramalan Dua Jenis Tahu

\begin{tabular}{lccc}
\hline Bulan & $\begin{array}{c}\text { Hasil Peramalan Tahu (Papan) } \\
\text { Tahu } \\
\text { Goreng }\end{array}$ & $\begin{array}{c}\text { Total } \\
\text { Tahu Potong }\end{array}$ \\
\hline 1 & 8680 & 4340 & 13020 \\
2 & 8680 & 4340 & 13020 \\
3 & 8680 & 4340 & 13020 \\
4 & 8260 & 4130 & 12390 \\
5 & 8260 & 4130 & 12390 \\
6 & 8540 & 4270 & 12810 \\
7 & 8540 & 4270 & 12810 \\
8 & 9590 & 4795 & 14385 \\
9 & 10675 & 5337.5 & 16012.5 \\
10 & 9765 & 4882.5 & 14647.5 \\
11 & 8540 & 4270 & 12810 \\
12 & 8540 & 4270 & 12810 \\
\hline Total & 115290 & 57645 & 108675 \\
\hline
\end{tabular}

Sumber: Usaha Pabrik Tahu Ma Onoh yang telah diolah

Dapat dilihat bahwa hasil peramalan diatas yaitu periode 1 bulan Desember banyaknya penjualan tahu goreng adalah 8680 papan, untuk tahu potong sebanyak 4340 papan. Dari hasil peramalan, dapat sebagai acuan untuk menentukan jadwal induk produksi. Hasil analisis untuk jadwal induk produksi dapat dilihat dibagian analisis, dan pada tabel 2. dan table.3.

Tabel 3. Jadwal Induk Produksi Tahu

\begin{tabular}{lrrr}
\hline \multicolumn{1}{c}{ Bulan } & \multicolumn{2}{c}{ Jadwal Induk Produksi Tahu } & \multirow{2}{*}{ Total } \\
\hline Gesember & 8680 & \multicolumn{1}{l}{ Potong } & 13020 \\
Januari & 8810 & 4340 & 13020 \\
Februari & 8810 & 4210 & 13020 \\
Maret & 8390 & 4000 & 12390 \\
April & 8384 & 4006 & 12390 \\
Mei & 8664 & 4146 & 12810 \\
Juni & 8668 & 4142 & 12810 \\
Juli & 9718 & 4667 & 14385 \\
Agustus & 10819 & 5194 & 16013 \\
September & 9925 & 4723 & 14648 \\
Oktober & 8686 & 4124 & 12810 \\
November & 8668 & 4142 & 12810 \\
Total & $\mathbf{1 0 8 2 2 2}$ & $\mathbf{5 1 9 0 4}$ & $\mathbf{1 6 0 1 2 6}$ \\
\hline
\end{tabular}

Sumber: Usaha Pabrik Tahu Ma Onoh yang telah diolah 


\section{sosio e-kons}

Volume 12, No. 3, Desember 2020, pp. 206-212

e-ISSN: $2502-5449$

p-ISSN: 2085-2266

DOI : $10.30998 /$ sosioekons.v12i3.6376

Setelah hasil analisis jadwal induk produksi tahu sudah diketahui, kemudian hasil jadwal induk produksi tersebut sebagai informasi untuk menentukan perencanaan dan pengendalian bahan baku produk tahu dengan menggunakan metode MRP teknik LFL. Dibawah ini pada tabel adalah hasil rangkuman kebutuhan bahan baku dan hasil analisis kebutuhan bahan baku produk tahu perbulan.

Tabel 4. Rangkuman Pemesanan Bahan Baku Tahu dengan Teknik LFL

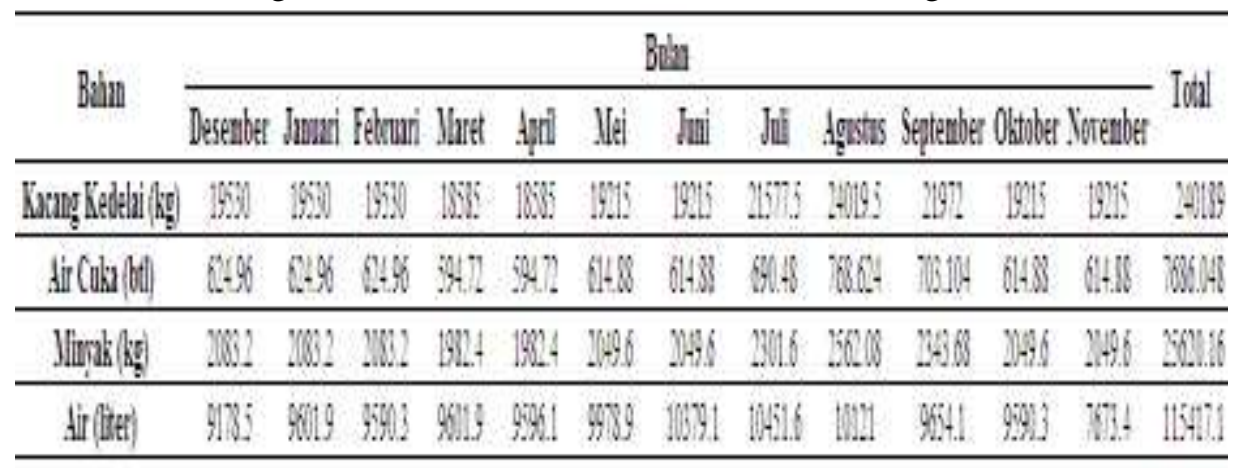

Sumber: Usaha Pabrik Tahu Ma Onoh yang telah diolah

Setelah hasil kebutuhan bahan baku untuk perbulan atau per periode sudah diketahui, dapat ditentukan untuk kebutuhan bahan baku perminggu. Pada tabel 4 yaitu hasil rangkuman pemesanan bahan baku dengan metode MRP teknik LFL.

Tabel 5. Rangkuman Pemesanan Bahan Baku Tahu untuk Jangka Waktu Perminggu

\begin{tabular}{|c|c|c|c|c|c|c|c|c|c|c|c|c|c|c|c|c|}
\hline Bulan & 1 & 2 & 3 & 4 & 5 & 6 & 7 & 8 & 9 & 10 & 11 & 12 & 13 & 14 & 15 & 16 \\
\hline Keoututhan Kotor & 4882.5 & 4882.5 & 4882.5 & 4882.5 & 4882.5 & 4882.5 & 4882.5 & 4882.5 & 4882.5 & 4882.5 & 4882.5 & 4882.5 & 4646.25 & 4646.25 & 4646.25 & 4646.25 \\
\hline Jadwal Penerimaan & 0 & 0 & 0 & 0 & 0 & 0 & 0 & 0 & 0 & 0 & 0 & 0 & 0 & 0 & 0 & 0 \\
\hline Persedtiaa Awal & 0 & 0 & 0 & 0 & 0 & 0 & 0 & 0 & 0 & 0 & 0 & 0 & 0 & 0 & 0 & 0 \\
\hline Keoduthan Bersih & 4882.5 & 4882.5 & 4882.5 & 4882.5 & 4882.5 & 4882.5 & 4882.5 & 4882.5 & 4882.5 & 4882.5 & 4882.5 & 4882.5 & 4646.25 & 4646.25 & 4646.25 & 4646.25 \\
\hline Jumlah Pemesanan & 4882.5 & 4882.5 & 4882.5 & 4882.5 & 4882.5 & 4882.5 & 4882.5 & 4882.5 & 4882.5 & 4882.5 & 4882.5 & 4882.5 & 4646.25 & 4646.25 & 4646.25 & 4646.25 \\
\hline Persedtaan Akhir & 0 & 0 & 0 & 0 & 0 & 0 & 0 & 0 & 0 & 0 & 0 & 0 & 0 & 0 & 0 & 0 \\
\hline Rencana Pemesanan & 4882.5 & 4882.5 & 4882.5 & 4882.5 & 4882.5 & 4882.5 & 4882.5 & 4882.5 & 4882.5 & 4882.5 & 4882.5 & 4882.5 & 4646.25 & 4646.25 & 4646.25 & 4646.25 \\
\hline
\end{tabular}

Sumber: Usaha Pabrik Tahu Ma Onoh yang telah diolah

Dari pembahasan analisis diatas, dapat dibuat perbandingan untuk perencanaan dan pengendalian bahan bakun produk tahu. Perencanaan dan pengendaliaan persediaan bahan baku tahu telah selesai dilakukan perhitungannya dengan menggunakan metode MRP teknik LFL. Pada dasarnya, penggunaan metode MRP bertujuan untuk menentukan kebutuhan bahan baku pada jumlah yang tepat, dan pada waktu yang tepat. Perhitungan dengan menggunakan teknik LFL dikarenakan teknik ini dapat meminimalisir biaya persediaan, dan biaya persediaan tersebut ada yg ditiadakan (nol), karena jumlah pemesanan dilakukan tepat sesuai dengan kebutuhan bersih yang diperlukan pada tiap periode. Pada tabel berikut, table 5 menunjukkan hasil rangkuman perbandingan biaya persediaan dengan teknik LFL dan biaya aktual di usaha produksi pembuatan tahu. 
Volume 12, No. 3, Desember 2020, pp. 206-212

e-ISSN: 2502-5449

p-ISSN: 2085-2266

DOI : 10.30998/sosioekons.v12i3.6376

Tabel 6. Rangkuman Hasil Perbandingan Biaya Persediaan (dalam Rupiah)

\begin{tabular}{lcccc}
\hline Teknik Lotting & $\begin{array}{c}\text { Total Biaya } \\
\text { Pemesanan }\end{array}$ & $\begin{array}{c}\text { Total Biaya } \\
\text { Penyimpanan }\end{array}$ & $\begin{array}{l}\text { Total Biaya } \\
\text { Pembelian }\end{array}$ & $\begin{array}{l}\text { Total Biaya } \\
\text { Persediaan } \\
\text { Keseluruhan }\end{array}$ \\
\hline $\begin{array}{l}\text { LFL } \\
\text { Perminggu }\end{array}$ & 1.440 .000 & 0 & $14.589 .079,86$ & $16.029 .079,86$ \\
$\begin{array}{l}\text { Biaya aktual } \\
\text { usaha produksi } \\
\text { tahu }\end{array}$ & 8.880 .000 & $18.275 .719,5$ & $1.474 .440 .000,00$ & $1.501 .595 .719,5$ \\
\hline
\end{tabular}

Sumber: Pengolah Data

Berdasarkan dari rangkuman total biaya persediaan yang dihasilkan dari perhitungan metode MRP teknik LFL sangat jauh lebih rendah dibandingkan pada total biaya aktual yang telah dikeluarkan oleh pihak usaha tahu sebelumnya. Penerapan MRP memberikan manfaat bagi perusahaan berupa penghematan biaya pengendalian persediaan. Penghematan dapat tercapai karena dalam sistem MRP menekankan tingkat persediaan bahan baku seminimal mungkin sesuai dengan kebutuhan. Usulan rekomendasi perencanaan dan pengendalian bahan baku dengan menggunakan metode MRP dalam jangka waktu perencanaan perminggu.

\section{Pembahasan Penelitian Terdahulu}

Menurut Fajriyah, Mu'tamar, \& Rahman, n.d. (2017). Perencanaan Persediaan Bahan Baku Rajungan Menggunakan Metode Materia Requirement Planning ( MRP) dengan menggunakan teknik Lot For Lot untuk mengetahui biaya pemesanan. Jurnal : Fakultas Pertanian, 10 (1) hlm. 9-15. Pengadaan bahan baku sering menjadi permasalahan dalam suatu industri. Pengadaan bahan baku yang baik dapat memperlancar jalannya suatu proses produksi sehingga kebutuhan dapat terpenuhi tepat waktu dan meminimalisasi biaya pengadaan. UD. Gerald Unedo yang terletak di Desa Sabiyan Bangkalan merupakan perusahaan yang bergerak di industri rajungan berproduksi sebagai pengulitan Rajungan. Pengadaan bahan baku metode perusahaan dilakukan berdasarkan apa yang biasa dilakukansebelumnya oleh perusahaan yaitu perusahaan akan memproduksi berapapun bahan baku yang tersedia pada suplier.Hasil yang telah dilakukan dengan metode MRP teknik Lot For Lot didapatkan biaya pemesanan sebesar Rp. 247. 470. 417 dan biaya penyimpanan sebesar Rp. 256. 700. 806 penghematan sebesar $44 \%$ lebih hemat dibandingkan dengan metode perusahan.

Menurut Saleh \& Dharmayanti, (2012). Penerapan Sistem Material Riquirement Planing (MRP ) pada sistem informasi pesanan dan inventory control. Jurnal: Program Studi Teknik Informatika Fakultas Teknik dan Ilmu Komputer Universitas Komputer Indonesia Jl. Dipati Ukur. Bandung. 1 (1) hlm. 112-116. CV ABC merupakan perusahan yang pertama kali memberikan layanan cetak digital dengan teknologi terkini, sekaligus yang pertama kali berdiri di Cilacap. Namun perusahaan tersebut sering mendapat masalah yang timbul diakibatkan oleh pengolahan data pesanan yang kurang terorganisir dan masih menggunakan formorder yang ditulis tangan. Ini mengakibatkan kurang efisiennya pekerjaan yang dikerjakan oleh banyak orang dengan mengandalkan form order. Kejadian ini sering terjadi dan berdampak pada konsumen yang complain akibat pesanan cetak digital yang dicetak tidak sesuai serta terlalu lama dikerjakan. Selain itu terkadang proses produksi terganggu akibat kurangnya bahan baku atau kelebihan bahan baku dan itu menyebabkan meningkatkan biaya produksi dan penurunan keuntungan perusahaan, kemudian transaksi yang dilakukan di dalam perusahaan tersebut juga kurang optimal dikarenakan belum terkomputerisasi. Untuk memecahkan masalah tersebut dibuatlah sistem informasi berbasis client-server yang hadir sebagai solusi yang paling efektif. 


\section{sosio e-kons}

Volume 12, No. 3, Desember 2020, pp. 206-212

e-ISSN: $2502-5449$

p-ISSN: 2085-2266

DOI : $10.30998 /$ sosioekons.v12i3.6376

\section{SIMPULAN}

Untuk membuat perencanaan dan pengendalian persediaan produk tahu, yaitu dengan cara menghitung, membahas, dan menganalisis. Hasil dari pembahasan dan analisa bahwa perencanaan dan pengendaliaan persediaan bahan baku dilakukan dengan menggunakan metode MRP. Secara keseluruhan, penerapan metode MRP ini memberikan hasil yang positif bagi perusahaan, selain untuk menghemat biaya persediaan, dan juga dapat menjamin kelancaran proses produksi sehingga proses produksi, berjalan secara efisien. Dari pembahasan yang telah dibahas, maka hasil dapat disimpulkan. Diketahui banyaknya bahan baku produk tahu yang dibutuhkan selama periode Desember 2018 sampai dengan November 2019 adalah $177600 \mathrm{kw}$ kacang kedelai, $23360 \mathrm{~kg}$ minyak goreng, dan 5920 botol air cuka. Selain itu, bahan-bahan penyusun produk tahu perlu diketahui sebagai informasi dalam membuat perencanaan persediaan bahan baku. Informasi bahan baku dibuat dalam bentuk struktur produk atau bill of materiall, hasil pembuatan bill of material adalah tahu goreng sebanyak 280 papan membutuhkan kacang kedelai sebanyak $400 \mathrm{~kg}$, minyak goreng sebanyak $64 \mathrm{~kg}$, air cuka 12 botol, dan air 676 liter. Kemudian tahu potong sebanyak $64 \mathrm{~kg}$ membutuhkan kedelai sebanyak $200 \mathrm{~kg}$, air cuka 8 botol, dan air 338 liter. Kemudian untuk hasil peramalan penjualan tahu goreng dan tahu potong selama periode Desember 2018 sampai dengan November 2019 adalah tahu goreng sebanyak 106.750 papan, dan tahu potong sebanyak 53.375 papan. Setelah mengetahui banyaknya penjualan, menetukan perencanaan agregat planning yaitu menentukan waktu produksi, waktu baku, biaya produksi dan kapasitas produksi. Waktu produksi dalam pembuatan tahu adalah 14 jam perhari, dengan waktu baku 0,03333 jam/papan, biaya produksi terdiri dari produksi normal sebesar Rp 1745,996/papan, biaya lembur sebesar Rp 285,71/papan, biaya penyimpanan $\mathrm{Rp} \mathrm{163,635/papan} \mathrm{per} \mathrm{bulan,} \mathrm{dan} \mathrm{kapasitas} \mathrm{produksi} \mathrm{tenaga} \mathrm{kerja} 12$ orang. Setelah menentukan perencanaan agregat planning diketahui, kemudian menentukan jadwal induk produksi dari periode Desember 2018 sampai dengan November 2019. Hasil perhitungan jadwal induk produksi dari periode Desember 2018 sampai dengan November 2019 adalah tahu goreng 108222 papan, dan tahu potong 51904 papan. Total biaya persediaan secara aktual adalah Rp 1.501.595.719,5 sedangkan total biaya persediaan yang telah dihitung menggunakan metode MRP teknik LFL adalah Rp 16.029.079,86.

\section{DAFTAR PUSTAKA}

Baroto. (2012). Perncanaan Dan Pengendalian Produksi. Jakarta: Ghalia Indonesia.

Fajriyah, E. W., Mu'tamar, M. F. F., \& Rahman, A. (n.d.).(2017). Perencanaan Persediaan Bahan Baku Rajungan Menggunakan Metode MRP (Material Requirement Planning. $J$. Rekayasa, vol 10(no1).

Gazpersz, \& Vincent. (2011). Product Planning and Inventory Control. Jakarta: Gramedia Pustaka.

Indrajit, \& Djokopranoto. (2013). Manajemen Persediaan. Jakarta: PT Gramedia Widiasarana Indonesia.

Saleh, F., \& Dharmayanti, D. (2012). Penerapan Material Requirement Planing (MRP) Pada Sistem Informasi Pesanan Dan Inventory Control Pada CV. ABC. J. Komputer Dan Informatika (KOMPUTA), vol 1.

Sofjan, A. (2014). Manajemen Produksi Dan Operasi. Jakarta: Fakultas Ekonomi Universitas Indonesia.

Sugiyono. (2015). Metode Penelitian Bisnis. Bandung: CV Alfabeta. 